\title{
Are There Consequences of Labeling Patients with Prehypertension? An Experimental Study of Effects on Blood Pressure and Quality of Life
}

\author{
Tanya M. Spruill, PhD ${ }^{1}$, Seth D. Feltheimer, MD², Manjunath Harlapur, MD ${ }^{3}$, Joseph E. \\ Schwartz, PhD ${ }^{2,4}$, Gbenga Ogedegbe, MD ${ }^{1}$, Youngjun Park, BS ${ }^{1}$, and William Gerin ${ }^{5}$ \\ ${ }^{1}$ Center for Healthful Behavior Change, Department of Population Health, New York University \\ School of Medicine \\ 2Division of General Medicine, Columbia University Medical Center \\ ${ }^{3}$ Department of Internal Medicine, University of California, San Francisco \\ ${ }^{4}$ Department of Psychiatry and Behavioral Science, Stony Brook University \\ ${ }^{5}$ Department of Biobehavioral Health, The Pennsylvania State University
}

\begin{abstract}
Objective-The prehypertension classification was introduced to facilitate prevention efforts among patients at increased risk for hypertension. Although patients who have been told they have hypertension report worse outcomes than unaware hypertensives, little is known about whether or not prehypertension labeling has negative effects. We evaluated the effects of labeling individuals with prehypertension on blood pressure and health-related quality of life three months later.
\end{abstract}

Methods-One hundred adults (aged 19 to 82 [mean=40.0] years; 54\% women; 64\% racial/ ethnic minorities) with screening blood pressure in the prehypertensive range (120-139/80-89 mm $\mathrm{Hg}$ ) and no history of diagnosis or treatment of elevated blood pressure were randomly assigned to either a "Labeled" group in which they were informed of their prehypertension, or an "Unlabeled" group in which they were not informed. Subjects underwent office blood pressure measurement, 24-hour ambulatory blood pressure monitoring and completed self-report questionnaires at baseline and three months.

Results-Multilevel mixed effects regression analyses indicated that changes in the white coat effect, office blood pressure, mean daytime ambulatory blood pressure, and physical and mental health did not differ significantly between the two groups. Adjusting for age, sex, race/ethnicity and body mass index did not affect the results.

Conclusion-These findings suggest that labeling patients with prehypertension does not have negative effects on blood pressure or quality of life. Additional research is needed to develop approaches to communicating with patients about their blood pressure that will maximize the clinical and public health impact of the prehypertension classification.

(C) 2012 Elsevier Inc. All rights reserved.

Corresponding Author: Tanya M. Spruill, PhD, New York University School of Medicine, 550 First Avenue VZ30, Room 640, New York, New York 10016. Tel: (646) 501-2619. Fax: (212) 263-4201. tanya.spruill@ nyumc.org.

DISCLOSURE: The authors have no conflicts of interest to report.

Publisher's Disclaimer: This is a PDF file of an unedited manuscript that has been accepted for publication. As a service to our customers we are providing this early version of the manuscript. The manuscript will undergo copyediting, typesetting, and review of the resulting proof before it is published in its final citable form. Please note that during the production process errors may be discovered which could affect the content, and all legal disclaimers that apply to the journal pertain. 


\section{Keywords}

prehypertension; white coat hypertension; ambulatory blood pressure monitoring; quality of life; blood pressure

\section{INTRODUCTION}

About one-third of U.S. adults have prehypertension (1), which is associated with an increased rate of progression to hypertension and increased cardiovascular disease (CVD) risk compared with normotension (2-6). Prior to the publication of the Seventh Report of the Joint National Committee on High Blood Pressure (JNC 7; 7), blood pressures (BP) in this range (120-139/80-89 mm Hg) were classified as "normal" or "high-normal" (8). Though it is not a disease category, the prehypertension classification was introduced to facilitate early identification of patients at increased risk for hypertension. Current treatment guidelines recommend counseling patients with prehypertension on the importance of lifestyle modification to reduce BP and prevent or delay progression to hypertension; the safety and efficacy of pharmacologic treatment in this group is the subject of ongoing investigation (913). As the pros and cons of treating BP to lower targets are debated (14), an important question to address is whether or not labeling patients with prehypertension has unintended negative consequences that could limit the potential benefits of early identification of elevated BP.

Observational studies of "hypertension labeling" have demonstrated a broad range of negative outcomes among patients who are aware of their hypertension status compared with those who are hypertensive but unaware of the diagnosis. Increases in work absenteeism (15-18), higher levels of physical symptoms $(18,19)$ and distress $(20-23)$, and lower health-related quality of life (23-28) have been reported, and are not explained by BP elevation itself or by drug treatment, suggesting that psychological effects of being labeled likely play a significant role. Much of the previous work on hypertension labeling has been limited by observational designs, which leave open a number of alternate interpretations such as the possibility that health declines or new physical symptoms prompt patients to seek medical attention and thus increase the opportunity for hypertension to be detected and diagnosed. The only published experimental studies of hypertension labeling demonstrated increased office BP among young men who were labeled as hypertensive following screening compared with those who were not informed of their diagnosis $(29,30)$. Ambulatory BP monitoring (ABPM) was not performed, so whether or not the increase was limited to the office setting (i.e., the white coat effect) is unknown. The white coat effect is defined as a transient increase in BP in the office setting relative to the usual BP, most often measured as the average daytime $A B P(31)$, and is a source of measurement error that can affect clinical decision making. In a previous observational study using ABPM, we found that the white coat effect was larger, on average, among aware versus unaware hypertensives, and this difference was partly explained by elevated anxiety in the office setting (32). The white coat effect might be particularly problematic among patients with prehypertension as it could contribute to the misdiagnosis of hypertension and unnecessary drug treatments.

The objective of the present study was to evaluate the effects of prehypertension labeling on the white coat effect and health-related quality of life three months later. One-hundred subjects, unaware of having elevated BP, were randomly assigned to either a "Labeled" group in which they were informed of their prehypertension status, or an "Unlabeled" group in which they (initially) were not informed. We hypothesized that subjects in the Labeled group would demonstrate greater increases in the white coat effect (i.e., higher office BP 
without changes in average daytime $\mathrm{ABP}$ ), and greater reductions in health-related quality of life than those in the Unlabeled group.

\section{METHOD}

\section{Study Population}

The target study population was healthy adults who were previously unaware of having elevated BP. Two recruitment strategies were used: (1) referrals from an internal medicine practice at Columbia University Medical Center (CUMC), and (2) advertisements for free BP screenings posted around the CUMC complex. Persons who responded to study advertisements or who were flagged by the physician (S.F.) were screened by a research assistant to determine eligibility. To avoid any possible labeling effect of participation, the research assistant described the purpose of the study as examining different ways that physicians talk to patients about their health; BP measurement was included in the explanation of procedures but was not the focus.

Screening and study visits were conducted in a private patient examination room. The primary inclusion criterion was a resting $\mathrm{BP}$, defined as the average of the last two of three BP measurements taken by the research assistant using an automated device (BpTRU, VSM Medtech, Model BPM-100), in the prehypertension range according to JNC 7 guidelines (120-139/80-89 mm Hg). To limit the sample to newly identified prehypertension, potential subjects were excluded if they reported ever having been informed of having elevated BP (i.e., hypertension, high BP or prehypertension) by a physician or ever having been prescribed antihypertensive medications. Those who reported a history of cardiovascular disease, diabetes or kidney disease were also excluded. Eligible subjects who wished to participate provided written informed consent and were scheduled for the baseline visit. The study protocol was approved by the CUMC Institutional Review Board and the study was conducted from July, 2009 through August, 2011.

\section{Study Procedures}

Baseline Visit-The research assistant measured the subject's height and weight and instrumented him/her with a Spacelabs 90207 ABP monitor (Spacelabs, Redmond, WA), a validated oscillometric device. After fitting the subject with an appropriately sized cuff on the non-dominant arm, the research assistant performed standard calibration procedures. $A s$ described below, the average of three resting calibration measurements taken with the $A B P$ monitor served as the office BP measure used to calculate the white coat effect for each study visit. The ABP monitors were programmed to collect and record (without display) BP data every 30 minutes for 24 hours, after which time subjects used prepaid mailers to return the equipment. Subjects also completed a battery of questionnaires at baseline, including demographic data, medical history and health-related quality of life using the SF-12 measure (33).

Randomization-Upon completion of the baseline visit, subjects were randomly assigned to one of two groups: (1) Unlabeled, in which the physician informed them of their BP level but did not give them a "prehypertension" label; or (2) Labeled, in which the physician informed them of their BP level and discussed prehypertension with them. A statistician determined group assignments using a computer-generated algorithm. The research assistant, who remained blinded, provided one of the study physicians (three total) with the top envelope from a stack of pre-prepared, sealed envelopes with the group assignment and corresponding script. The scripts for both groups were developed in collaboration with several physicians to be as realistic as possible with regard to length and content of feedback. 
UNLABELED: "First, let me explain that a person's blood pressure varies for a lot of reasons, like drinking coffee or running around a lot or being stressed. Your blood pressure today is in the high normal range, but we don't pay much attention to a single reading. We'll measure your blood pressure again three months from now to see how you're doing.

$L A B E L E D$ : "First, let me explain that a person's blood pressure varies for a lot of reasons, like drinking coffee or running around a lot or being stressed. Your blood pressure today is in what is called the 'pre-hypertension' range. This doesn't mean that you have hypertension, and you don't need to take medication at this point. However, it does mean that you are at increased risk for developing hypertension in the future. Hypertension is a serious condition that can cause stroke, heart disease, or kidney disease, and it must be treated. To prevent your blood pressure from increasing to that level, there are things you can do, like losing weight, exercising more, and eating less salt. If your blood pressure does increase in the future, I might recommend that we consider treating you with anti-hypertension medication. We'll measure your blood pressure again three months from now, and if it's still high, we'll discuss how to proceed."

The decision to inform subjects in both groups of their BP may result in a smaller labeling effect than if one group was provided no feedback at all. However, this control condition is more consistent with a real clinical encounter in which patients are often told their BP level when it is measured and given minimal feedback when it is below the threshold for hypertension. The question addressed in this study was whether the prehypertension label and accompanying risk information have an impact on patients above and beyond the minimal feedback they typically receive.

3-Month Visit-Subjects were scheduled to complete a follow-up visit three months after their baseline visit. At this time 24-hour ABPM and self-report questionnaires were repeated to obtain follow-up measures of the white coat effect and health-related quality of life. A brief questionnaire was also administered to assess diagnoses or treatments that may have occurred since the baseline visit. Subjects were debriefed about the purpose of the study at the end of the three-month visit, and those assigned to the Unlabeled group were given the information the Labeled group previously received; individual feedback was tailored based on current BP. Subjects received $\$ 50$ compensation for completing each study visit for a possible total of $\$ 100$.

\section{Statistical Analysis}

Sample size calculations-Power calculations indicated that 45 subjects per group (90 total) would provide 93/90\% power to detect group differences of $12 / 7 \mathrm{~mm} \mathrm{Hg}$ in the systolic/diastolic white coat effect, using two-tailed, $\alpha=.05$ level F-tests. These estimates were based on the experimental study of hypertension labeling conducted by Rostrup et al. (29); given differences in the study designs, we reduced the expected effect sizes by $25 \%$. Standard deviations were estimated using previously collected longitudinal office BP and ABP data (34). We recruited a sample of 100 to allow for attrition at follow-up and other potential problems (e.g., insufficient ABP data) for $10 \%$ of subjects.

Outcome Variables-The primary study outcome was the white coat effect, computed as the difference between office BP and the average daytime ABP (31). Office BP was defined as the average of three resting BP measurements taken by the research assistant with the $\mathrm{ABP}$ monitor during calibration at each study visit. This approach allows calculation of the white coat effect using a measure of office BP that is obtained using the same device as the $\mathrm{ABP}$ measure. The ABP measure was computed as the average of all awake readings during 
the monitoring period based on subject diaries; if sleep and wake times were not reported, the daytime period was defined as 7AM to 10PM. The mean number of awake ABP readings was $22.9(\mathrm{SD}=5.7)$ at baseline and $20.0(\mathrm{SD}=7.2)$ at three months.

The secondary outcome was health-related quality of life, assessed with the Short Form (SF)-12, a validated and widely-used self-report measure (33). The SF-12 yields eight subscales representing various domains of functioning, which are combined to create Physical Component Summary (PCS) and Mental Component Summary (MCS) measures. Each subscale contributes to both summary measures, but physical functioning, physical role limitation, bodily pain and general health are weighted more heavily in the PCS score, while mental health, emotional role limitation, social function and vitality are weighted more heavily in the MCS score. PCS and MCS scores are transformed based on U.S. normative data to a mean of 50 and standard deviation of 10 , where higher scores reflect better functioning.

Analysis Plan-Descriptive statistics were used to characterize the sample and test for any group differences at baseline. Linear multilevel repeated-measures regression analyses were performed to generate full-information maximum-likelihood estimates of labeling effects on the changes the white coat effect, separate office BP and ABP measures, and health-related quality of life from baseline to three months (Group X Time interactions). Following the primary analyses, we examined the effects of prehypertension labeling on each of the outcome measures after adjusting for a set of relevant covariates (age, sex, race/ethnicity, body mass index). Analyses were performed using SPSS v.20.

\section{RESULTS}

Figure 1 shows the study flowchart. Of the 100 subjects who were enrolled and randomized, 71 completed the three-month follow-up visit; the dropout rate did not differ by group $\left(\chi^{2}=0.44, \mathrm{df}=1, P=0.51\right)$. Inability to recontact subjects was the primary reason for loss to follow-up, and several subjects moved or withdrew from the study. There were no significant differences between subjects who dropped out and those who completed the study with regard to demographic characteristics (age, sex, race/ethnicity; $P \mathrm{~s}>0.75$ ), the white coat effect $(P \mathrm{~s}>0.20)$, office $\mathrm{BP}(P \mathrm{~s}>0.77)$, daytime systolic $\mathrm{BP}(P=0.36)$, or healthrelated quality of life $(P \mathrm{~s}>0.60)$; however, subjects who dropped out had higher body mass index $\left(29.3 \mathrm{~kg} / \mathrm{m}^{2}\right.$ vs. $\left.25.7 \mathrm{~kg} / \mathrm{m}^{2}, P=0.02\right)$ and lower daytime diastolic BP $(76.1 \mathrm{~mm} \mathrm{Hg}$ vs. $79.1 \mathrm{~mm} \mathrm{Hg}, P=0.04$ ) compared with those who completed the study.

\section{Sample characteristics}

The enrolled sample was racially and ethnically diverse, with $42 \%$ Hispanic subjects, $36 \%$ non-Hispanic whites, $12 \%$ non-Hispanic blacks, $7 \%$ Asian and 3\% other races. The age range was 19 to 82 years with a mean of 40.0 years ( $\mathrm{SD}=14.3$ ), and $54 \%$ of subjects were women. As shown in Table 1, demographic characteristics of the two experimental groups were similar. There were no significant group differences at baseline in office BP, the white coat effect or mental health, but subjects in the Labeled group reported better physical health than those in the Unlabeled group (PCS $=50.5$ vs. $47.8, P=0.02$ ) and had somewhat higher average daytime diastolic BP (79.5 $\mathrm{mm} \mathrm{Hg}$ vs. $77.0 \mathrm{~mm} \mathrm{Hg}, P=0.06)$.

\section{Effects of prehypertension labeling}

Results of the primary intent-to-treat analysis of change in the white coat effect from baseline to three months are presented in Table 2. Although the use of mixed effects regression allows inclusion of subjects with missing follow-up data, three subjects who dropped out were not included in this analysis because missing BP data prevented 
calculation of a baseline white coat effect. On average, the systolic white coat effect increased by $2.2 \mathrm{~mm} \mathrm{Hg}$ in the Labeled group and decreased by $1.0 \mathrm{~mm} \mathrm{Hg}$ in the Unlabeled group, while the diastolic white coat effect was essentially unchanged in both groups; as shown in Table 2, the Group X Time interaction was not statistically significant for either outcome $(P \mathrm{~s}>0.30)$. There were also no significant differences in the effects of prehypertension labeling on the separate measures of office $\mathrm{BP}\left(P_{\mathrm{s}}>0.48\right)$ or mean daytime $\operatorname{ABP}(P \mathrm{~s}>0.39)$.

For descriptive purposes, we also examined changes in BP classification by study group. By design, all subjects were prehypertensive at baseline; the majority of subjects in both groups continued be classified as prehypertensive at the three-month follow-up based on office $B P$ (58.8\% Labeled, 54.5\% Unlabeled). A higher proportion of Labeled versus Unlabeled subjects were classified as hypertensive at follow-up (17.6\% Labeled, $12.1 \%$ Unlabeled) and fewer Labeled subjects were classified as normotensive (23.5\% Labeled, 33.3\% Unlabeled). However, consistent with the results based on continuous BP measures, group differences in office BP classification at follow-up were not statistically significant $\left(\chi^{2}=0.96, d f=2\right.$, $P=0.62$ ). There was also no significant difference in the proportion of Labeled and Unlabeled subjects who met criteria for white coat hypertension at three months $(\mathrm{P}=0.49)$.

Next, we tested the effects of prehypertension labeling on health-related quality of life. One subject who dropped out of the study had missing SF-12 data at baseline and thus was not included in these analyses. Results of this set of mixed effects regression analyses indicated that prehypertension labeling did not significantly influence self-reported physical or mental health. The average PCS score decreased by 1.7 in the Labeled group and by 0.6 in the Unlabeled group ( $P=0.24$ for the Group X Time interaction), and the average MCS score decreased by 0.2 in the Labeled group and increased by 2.1 in the Unlabeled group $(P=0.34$ for the Group X Time interaction).

As shown in Table 2, the magnitude and significance level of the effects of labeling on each of the outcomes did not change substantially when we adjusted for age, sex, race/ethnicity and body mass index. The follow-up questionnaire indicated that none of the subjects began taking antihypertensive medication between the baseline and three-month visits. However, at the three-month visit, two subjects (one in each group) reported that they had in fact had high BP diagnosed and/or treated prior to enrolling in the study. Repeating the primary analyses without these two subjects revealed no change in the significance of any of the findings. Although we did not power the study to detect interactions, we were also interested in exploring whether the effects of prehypertension labeling differed by race/ethnicity, given our previous work demonstrating race differences in the effects of hypertension awareness (23). The Group X Time X Race/ethnicity (non-Hispanic white vs. minority) interaction was not statistically significant for the systolic or diastolic white coat effect $\left(P_{\mathrm{S}}>0.30\right)$, office BP $(P \mathrm{~S}>0.77)$, mean daytime ABP $\left(P_{\mathrm{S}}>0.68\right)$ or physical or mental health $(P \mathrm{~s}>0.49)$, indicating that prehypertension labeling had minimal effects among both white and minority participants.

\section{DISCUSSION}

The detection of prehypertension is intended to improve patients' health outcomes by delaying the onset of hypertension. However, evidence of the negative effects of hypertension labeling has led to questions regarding the potential consequences of labeling patients at even lower BP levels (35). Contrary to our hypothesis, results of this randomized, controlled study suggest that prehypertension labeling does not negatively affect patients. Specifically, labeling did not lead to increases in the white coat effect, office BP or ABP, and there were no differences in the proportion of Labeled and Unlabeled prehypertensive 
participants who met criteria for white coat hypertension at three months. Changes in selfreported physical and mental health also did not differ between the groups. These findings suggest that the potential benefits of early identification of prehypertension are unlikely to be limited by unintended consequences of labeling patients.

Only one other published study has investigated the effects of prehypertension labeling. Using a similar design, Viera et al. (36) randomly assigned newly identified prehypertensive patients to labeled or unlabeled groups and examined changes in perceived health and adoption of recommended lifestyle modifications three months later. They found no differences between the groups with regard to self-reported changes in exercise or dietary behaviors, and consistent with our findings, there was no evidence that prehypertension labeling adversely affected patients' perceived health. Thus, the previously reported negative effects of hypertension awareness on health-related quality of life (23-28) do not appear to extend to prehypertension. Whether this discrepancy reflects the perceived severity of a hypertension diagnosis, patients' feelings about the need for drug treatment, differences in patient-physician communication, or some combination, is unknown.

To our knowledge, ours is the first study to examine effects of prehypertension labeling on BP. Rostrup et al. $(29,30)$ found significant increases in office BP among labeled versus unlabeled hypertensive subjects, although ABPM was not performed so changes in the white coat effect could not be assessed. Still, effects of labeling on office BP were much smaller in our study. In addition to the significance of the label itself (i.e., hypertension vs. prehypertension), differences in the study designs may have contributed to this discrepancy. The present study involved a more active comparison condition, and subjects were assessed three months after being labeled, compared with two weeks in the Rostrup study. On the other hand, labeling was performed in-person by a physician in the present study rather than via mailed letters in the Rostrup study. Again, it is also likely that subjects' health beliefs and level of knowledge about prehypertension played a role. How patients interpret diagnostic and risk information is an important question for future research that may help to explain behavioral and psychological responses to labeling.

The present study is one of the few experimental investigations of either prehypertension or hypertension labeling that have been conducted to date. This is an important strength, however labeling is a complicated phenomenon to study and there is no ideal design. While the use of scripted physician messages was important for experimental control, the feedback physicians provide in the real world may differ in meaningful ways. Also, the fact that subjects in both groups received some feedback about their BP may have resulted in a smaller labeling effect than if one group was provided no feedback at all. This design reflects the primary aim of the study, which was to determine whether being labeled as prehypertensive by a physician and informed of the associated health risks would have a greater effect on subjects than the minimal level of feedback they would likely receive in usual clinical care.

Several other limitations must be noted. First, the follow-up period was relatively short, and it is possible that effects of labeling may emerge later. We chose three months because this is a typical follow-up interval for monitoring BP in this range in primary care settings, and because of ethical concerns regarding withholding diagnostic information for longer than three months. Second, although the dropout rate did not differ by group, it is possible that subjects who did not return for the follow-up visit were those who were most affected by the feedback (either version), thereby underestimating the effects of labeling. Finally, we could not verify that subjects had never been informed of having high BP prior to enrolling in the study. Two subjects indicated a previous history of labeling after being enrolled and there may have been others who did not report this to us. 


\section{Conclusions}

Results of the current study indicate that labeling patients with prehypertension does not negatively affect their BP or quality of life, at least in the short-term. Given that more than one-third of U.S. adults have prehypertension, the potential impact of targeting prevention efforts among this group is substantial. Prehypertension is associated with a low prevalence of healthy lifestyle behaviors (37), and positive effects of lifestyle modification among this group have been demonstrated (38-40). However, little is currently known about how often physicians use the prehypertension classification when treating patients (41), and how patients recall and respond to this information. Recent findings indicate that labeling patients with prehypertension does not increase lifestyle modification (36), suggesting that while using this classification may not be harmful to patients, it is also not particularly helpful. Additional research is needed to determine approaches to communicating with patients about their BP that will increase the likelihood of behavior change and lead to improved health outcomes.

\section{Acknowledgments}

This research was supported by grants from the National Institutes of Health/National Heart, Lung and Blood Institute (K23HL086734, P01HL47540, R24HL76857). The authors also acknowledge the contributions of Thomas G. Pickering, who was a mentor on the K23 award that funded this study.

\section{References}

1. Wang Y, Wang QJ. The prevalence of prehypertension and hypertension among U.S. adults according to the new Joint National Committee Guidelines. Arch Intern Med. 2004; 164:2126-34. [PubMed: 15505126]

2. Vasan RS, Larson MG, Leip EP, Kannel WB, Levy D. Assessment of frequency of progression to hypertension in non-hypertensive participants in the Framingham Heart Stuy: a cohort study. Lancet. 2001; 358:1682-6. [PubMed: 11728544]

3. Vasan RS, Larson MG, Leip EP, Evans JC, O’Donnell CJ, Kannel WB, Levy D. Impact of highnormal blood pressure on the risk of cardiovascular disease. N Engl J Med. 2001; 345:1291-7. [PubMed: 11794147]

4. Qureshi AI, Suri MF, Kirmani JF, Divani AA, Mohammad Y. Is prehypertension a risk factor for cardiovascular diseases? Stroke. 2005; 36:1859-63. [PubMed: 16081866]

5. Mainous AG, Everett CJ, Liszka H, King DE, Egan BM. Prehypertension and mortality in a nationally representative cohort. Am J Cardiol. 2004; 94:1496-500. [PubMed: 15589003]

6. Greenlund KJ, Croft JB, Mensah GA. Prevalence of heart disease and stroke risk factors in persons with prehypertension in the United States, 1999-2000. Arch Intern Med. 2004; 164:2113-8. [PubMed: 15505124]

7. Chobanian AV, Bakris GL, Black HR, Cushman WC, Green LA, Izzo JL, Jones DW, Materson BJ, Oparil S, Wright JT, Roccella EJ. the National High Blood Pressure Education Program Coordinating Committee. The Seventh Report of the Joint National Committee on Prevention, Detection, Evaluation, and Treatment of High Blood Pressure. Hypertension. 2003; 42:1206-52. [PubMed: 14656957]

8. Joint National Committee on Prevention, Detection Evaluation, and Treatment of High Blood Pressure and the National High Blood Pressure Education Program Committee (1997). . The sixth report of the Joint National Committee on Prevention, Detection, Evaluation, and Treatment of High Blood Pressure (JNC 6). Arch Intern Med. 1997; 157:2413-46. [PubMed: 9385294]

9. Julius S, Nesbitt SD, Egan BM, Weber MA, Michelson EL, Kaciroti N, Black HR, Grimm RH, Messerli FH, Oparil S, Schork MA. Trial of Preventing Hypertension (TROPHY) Study Investigators. Feasibility of treating prehypertension with an angiotensin-receptor blocker. N Engl J Med. 2006; 354:1685-97. [PubMed: 16537662]

10. Luders S, Schrader J, Berger J, Unger T, Zidek W, Bohm M, Middeke M, Motz W, Lubcke C, Gansz A, Brokamp L, Schmieder RE, Trenkwalder P, Haller H, Dominiak P. PHARAO Study 
Group. The PHARAO study: prevention of hypertension with the angiotensin-converting enzyme inhibitor ramipril in patients with high-normal blood pressure: a prospective, randomized, controlled prevention trial of the German Hypertension League. J Hypertens. 2008; 26:1487-96. [PubMed: 18551027]

11. Sipahi I, Swaminathan A, Natesan V, Debanne SM, Simon DI, Fang JC. Effect of antihypertensive therapy on incident stroke in cohorts with prehypertensive blood pressure levels: a meta-analysis of randomized controlled trials. Stroke. 2012; 43:432-40. [PubMed: 22156683]

12. Nissen SE, Tuzcu EM, Libby P, Thompson PD, Ghali M, Garza D, Berman L, Shi H, Buebendorf E, Topol EJ. CAMELOT Investigators. Effect of antihypertensive agents on cardiovascular events in patients with coronary disease and normal blood pressure: the CAMELOT study: a randomized controlled trial. JAMA. 2004; 292:2217-25. [PubMed: 15536108]

13. Thompson AM, Hu T, Eshelbrenner CL, Reynolds K, He J, Bazzano LA. Antihypertensive treatment and secondary prevention of cardiovascular disease events among persons without hypertension: a meta-analysis. JAMA. 2011; 305:913-22. [PubMed: 21364140]

14. Chobanian AV. Mixed messages on blood pressure goals. Hypertension. 2011; 57:1039-40. [PubMed: 21555679]

15. Haynes RB, Sackett DL, Taylor DW, Gibson ES, Johnson AL. Increased absenteeism from work after detection and labeling of hypertensive patients. N Engl J Med. 1978; 299:741-4. [PubMed: 692548]

16. Alderman MH, Charlson ME, Melcher LA. Labelling and absenteeism: the Massachusetts Mutual experience. Clin Invest Med. 1981; 4:165-71. [PubMed: 7337987]

17. Leynen F, De Backer G, Pelfrene E, Clays E, Kittel F, Moreau M, Kornitzer M. Increased absenteeism from work among aware and treated hypertensive and hypercholesterolaemic patients. Eur J Cardiovasc Prev Rehabil. 2006; 13:261-7. [PubMed: 16575282]

18. Melamed S, Froom P, Green MS. Hypertension and sickness absence: the role of perceived symptoms. J Behav Med. 1997; 20:473-87. [PubMed: 9415857]

19. Stewart JC, France CR, Sheffield D. Hypertension awareness and pain reports: data from the NHANES III. Ann Behav Med. 2003; 26:8-14. [PubMed: 12867349]

20. Bloom JR, Monterossa S. Hypertension labeling and sense of well-being. Am J Public Health. 1981; 71:1228-32. [PubMed: 7294265]

21. Reiff M, Schwartz S, Northridge M. Relationship of depressive symptoms to hypertension in a household survey in Harlem. Psychosom Med. 2001; 63:711-21. [PubMed: 11573017]

22. Hamer M, Batty GD, Stamatakis E, Kivimaki M. Hypertension awareness and psychological distress. Hypertension. 2010; 56:547-50. [PubMed: 20625078]

23. Spruill TM, Gerber LM, Schwartz JE, Pickering TG, Ogedegbe G. Race differences in the physical and psychological impact of hypertension labeling. Am J Hypertens. 2012; 25:458-63. [PubMed: 22258335]

24. Hayes DK, Denny CH, Keenan NL, Croft JB, Greenlund KJ. Health-related quality of life and hypertension status, awareness, treatment, and control: National Health and Nutrition Examination Survey, 2001-2004. J Hypertens. 2008; 26:641-7. [PubMed: 18327071]

25. Barger SD, Muldoon MF. Hypertension labelling was associated with poorer self-rated health in the Third US National Health and Nutrition Examination Survey. J Hum Hypertens. 2006; 20:117-23. [PubMed: 16267563]

26. Banegas JR, Guallar-Castillon P, Rodriguez-Artalejo, Graciani A, Lopez-Garcia E, Ruilope LM. Association between awareness, treatment, and control of hypertension and quality of life among older adults in Spain. Am J Hypertens. 2006; 19:686-93. [PubMed: 16814122]

27. Li W, Liu L, Puente JG, Li Y, Jiang X, Jin S, Ma H, Kong L, Ma L, He X, Ma S, Chen C. Hypertension and health-related quality of life: an epidemiological study in patients attending hospital clinics in China. J Hypertens. 2005; 23:1667-76. [PubMed: 16093911]

28. Mena-Martin FJ, Martin-Escudero JC, Simal-Blanco F, Carretero-Ares JL, Arzua-Mouronte D, Herreros-Fernandez V. Health-related quality of life of subjects with known and unknown hypertension: results from the population-based Hortega study. J Hypertens. 2003; 21:1283-9. [PubMed: 12817174] 
29. Rostrup M, Ekeberg O. Awareness of high blood pressure influences on psychological and sympathetic responses. J Psychosom Res. 1992; 36:117-23. [PubMed: 1560424]

30. Rostrup M, Kjeldsen SE, Eide IK. Awareness of high blood pressure increases blood pressure and sympathetic responses to cold pressor test. Am J Hypertens. 1990; 3:912-7. [PubMed: 2081012]

31. Pickering TG, Hall JE, Appel LJ, Falkner BE, Graves J, Hill MN, Jones DW, Kurtz T, Sheps SG, Roccella EJ. Recommendations for blood pressure measurement in humans and experimental animals. Part 1: Blood pressure measurement in humans: a statement for professionals from the Subcommittee of Professional and Public Education of the American Heart Association Council on High Blood Pressure Research. Circulation. 2005; 111:697-716. [PubMed: 15699287]

32. Spruill TM, Pickering TG, Schwartz JE, Mostofsky E, Ogedegbe G, Clemow L, Gerin W. The impact of perceived hypertension status on anxiety and the white coat effect. Ann Behav Med. 2007; 34:1-9. [PubMed: 17688391]

33. Ware J, Kosinski M, Keller SD. A 12-item short-form health survey: construction of scales and preliminary tests of reliability and validity. Med Care. 1996; 34:220-33. [PubMed: 8628042]

34. Ogedegbe G, Pickering TG, Clemow L, Chaplin W, Spruill TM, Eguchi K, Burg M, Gerin W. The misdiagnosis of hypertension: the role of conditioned patient anxiety. Arch Intern Med. 2008; 168:2459-65. [PubMed: 19064830]

35. Ogedegbe G. Labeling and hypertension: it is time to intervene on its negative consequences. Hypertension. 2010; 56:344-5. [PubMed: 20625073]

36. Viera AJ, Lingley K, Esserman E. Effects of labeling patients as prehypertensive. J Am Board Fam Med. 2010; 23:571-83. [PubMed: 20823351]

37. Greenlund KJ, Daviglus ML, Croft JB. Differences in healthy lifestyle characteristics between adults with prehypertension and normal blood pressure. J Hypertens. 2009; 27:955-62. [PubMed: 19293725]

38. Appel LJ, Champagne CM, Harsha DW, Cooper LS, Obarzanek E, Elmer PJ, Stevens VJ, Vollmer WM, Lin PH, Svetkey LP, Stedman SW, Young DR. Writing Group of the PREMIER Collaborative Research Group. Effects of comprehensive lifestyle modification on blood pressure control: main results of the PREMIER clinical trial. JAMA. 2003; 289:2083-93. [PubMed: 12709466]

39. Prather AA, Blumenthal JA, Hinderliter AL, Sherwood A. Ethnic differences in the effects of the DASH diet on nocturnal blood pressure in individuals with high blood pressure. Am J Hypertens. 2011; 24:1338-44. [PubMed: 21866183]

40. Faselis C, Doumas M, Kokkinos JP, Panagiotakos D, Kheirbek R, Sheriff HM, Hare K, Papademetriou V, Fletcher R, Kokkinos P. Exercise capacity and progression from prehypertension to hypertension. Hypertension. 2012; 60:333-8. [PubMed: 22753224]

41. Viera AJ, Bangura F, Mitchell CM, Cerna A, Sloane P. Do clinicians tell patients they have prehypertension? J Am Board Fam Med. 2011; 24:117-8. [PubMed: 21209353] 


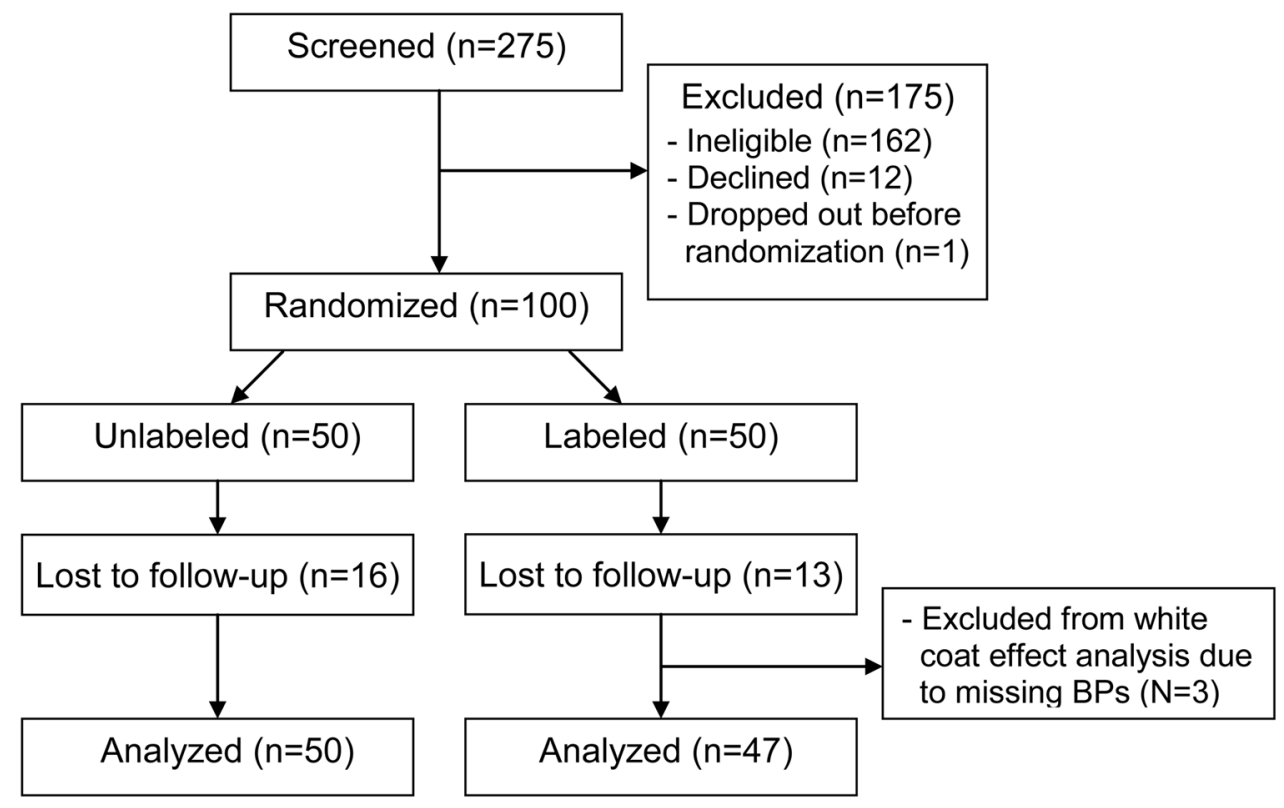

Figure 1.

Study flow chart. 
Table 1

Baseline characteristics by group

\begin{tabular}{lccc}
\hline & Unlabeled (N=50) & Labeled (N=50) & $\boldsymbol{P}^{*}$ \\
\hline Age, years & $39.7(16.4)$ & $40.2(12.1)$ & 0.84 \\
Sex, \% (N) female & $60.0 \%(30)$ & $48.0 \%(24)$ & 0.23 \\
Race/ethnicity, \% (N) minorities & $66.0 \%(33)$ & $62.0 \%(31)$ & 0.68 \\
BMI, kg/m² & $26.9(5.8)$ & $26.5(5.5)$ & 0.73 \\
White coat effect, systolic, mm Hg & $3.6(10.4)$ & $2.0(9.7)$ & 0.44 \\
White coat effect, diastolic, mm Hg & $2.0(9.4)$ & $1.0(8.4)$ & 0.56 \\
Office BP, systolic, mm Hg & $126.7(12.1)$ & $126.0(12.5)$ & 0.76 \\
Office BP, diastolic, mm Hg & $79.1(8.2)$ & $80.7(9.3)$ & 0.37 \\
Mean daytime ABP, systolic, mm Hg & $123.0(7.5)$ & $124.2(9.3)$ & 0.46 \\
Mean daytime ABP, diastolic, mm Hg & $77.0(6.8)$ & $79.5(6.1)$ & 0.06 \\
Physical health (SF-12, PCS) & $47.8(6.9)$ & $50.5(3.6)$ & 0.02 \\
Mental health (SF-12, MCS) & $46.3(9.2)$ & $46.9(6.1)$ & 0.69 \\
\hline
\end{tabular}

Note: Data are presented as mean (SD) unless otherwise indicated.

Based on independent-sample $t$ test for continuous variables and $\chi^{2}$ test for categorical variables. 
